\title{
CANCER
}

\section{Frequency of hereditary non-polyposis colorectal cancer in Danish colorectal cancer patients}

\author{
N Katballe, M Christensen, F P Wikman, T F Ørntoft, S Laurberg
}

Gut 2002;50:43-51

See end of article for authors' affiliations

Correspondence to: Dr N Katballe, Surgical Research Unit, afd. 900, Department of Surgery L, Aarhus Amtssygehus, Aarhus University Hospital, Tage Hansens Gade 2, 8000 Aarhus C, Denmark

Accepted for publication 12 April 2001
Background: Hereditary non-polyposis colorectal cancer (HNPCC) is an autosomal dominant cancer syndrome, characterised by familial aggregation of HNPCC related cancers, germline mutations in mismatch repair genes, and/or microsatellite instability (MSI) in tumour tissue.

Aim: To estimate the frequency of HNPCC among non-selected Danish patients with colorectal cancer (CRC), and to evaluate the value of MSI analysis as a pre-screen test.

Methods: This was a prospective population based study on consecutive CRC patients. A family history of malignancy was obtained and suspected HNPCC cases were screened for hMLH1/hMSH2 mutations and subjected to MSI analysis. Patients with germline mutations and/or those with Amsterdam criteria I or II families were categorised as HNPCC patients.

Results: Among 1328 eligible CRC patients, 1200 (90.4\%) completed a questionnaire. A total of $1.7 \%$ (95\% confidence interval (CI) 1.0-2.4) (20 cases) were categorised as HNPCC patients. Amsterdam criteria I or II were met in 18 cases $(1.5 \%)$, and in another two cases $(0.2 \%)$ pathogenic hMLHI / hMSH2 mutations were detected without fulfilment of the Amsterdam criteria I or II. Among 77 patients younger than 50 years of age, 11 cases (14.3\%) were categorised as HNPCC. The Amsterdam criteria I or II were met in eight of 10 gene carriers (80\%). The MSI-high phenotype was demonstrated in all 10 gene carriers.

Conclusion: The frequency of HNPCC was approximately $1.7 \%$ among all CRC cases and $14.3 \%$ among patients younger than 50 years of age. MSI analysis is a reliable pre-screen test for hMLH1/ hMSH2 mutations in families suspected of having HNPCC.
$\mathrm{T}$ he first known hereditary non-polyposis colorectal cancer (HNPCC) family, "family G", was described by the Michigan pathologist Aldred Scott Warthin in 1913. ${ }^{1}$ Family G was revisited by Henry T Lynch in $1971 .^{2}$ Lynch et al described two hereditary colon cancer syndromes: Lynch syndrome 1, where colon cancer was the only occurring malignancy; and Lynch syndrome 2, which was characterised by a high risk of colorectal cancer (CRC) but also of other extracolonic cancers, especially cancer of the endometrium, stomach, ovary, urinary tract, and other gastrointestinal cancers. ${ }^{3-6}$ The term HNPCC was developed to encompass Lynch syndromes 1 and 2 . In 1991, the International Collaborative Group on HNPCC (ICGHNPCC) proposed clinical criteria for HNPCC, the so-called Amsterdam criteria I: (1) at least three histologically verified CRCs in at least two successive generations; (2) at least one family member must be diagnosed before the age of 50 years; (3) at least one family member must be a first degree relative to the two others; and (4) familial adenomatous polyposis must be excluded. ${ }^{7}$ Recently, new clinical criteria for HNPCC, the Amsterdam criteria II, were proposed by the ICG-HNPCC. The Amsterdam criteria II extend the tumour spectrum to include endometrial cancer, small bowel cancer, ureter cancer, and renal pelvis cancer. Those who meet Amsterdam criteria I or II are likely to represent HNPCC families. ${ }^{8}$

Pathogenic germline mutations in mismatch repair (MMR) genes are detected in 50\% of families who meet the Amsterdam criteria I. ${ }^{9}$ Since 1993, five HNPCC genes (mutator $\mathrm{S}$ homologue gene 2 ( $\mathrm{h}=$ human) HNPCC gene (hMSH2); mutator $\mathrm{S}$ homologue gene 6 (h=human) HNPCC gene (hMSH6); mutator L homologue gene ( $\mathrm{h}=$ human), HNPCC gene (hMLH1); and human homologue of yeast postmeiotic segregation genes 1 and 2 (hPMS1 and hPMS2)) have been cloned and mapped. ${ }^{10-16}$ The vast majority of pathogenic mutations in HNPCC families are detected in hMLHl and hMSH2. ${ }^{17}$ Very few cases have been reported in hPMSI and
hPMS2. ${ }^{15}$ Germline mutations in hMSH6 tend to generate a phenotype with later onset of CRC, and are detected in about 5\% of HNPCC suspected families. ${ }^{10} 141920$

The tumour tissue from HNPCC patients harbouring pathogenic mutations in the MMR genes is frequently characterised by microsatellite instability (MSI). ${ }^{21-23}$ MSI can be categorised as MSI-H (high), MSI-L (low), or MS-S (stable)..$^{24}$ Carriers of pathogenic hMLHl/hMSH2 germline mutations frequently show MSI-H in tumour tissue. ${ }^{22} 232526$ Although carriers of hMSH6 germline mutations also frequently present with the MSI-H phenotype, they have a tendency to present with the MSI-L phenotype. ${ }^{10}{ }^{14} 27$ This was demonstrated by Wu et al who detected hMSH6 germline mutations in four of 18 (22\%) MSI-L tumours from patients with a suspected HNPCC family history. ${ }^{28}$ The results of MSI testing depends on the choice of microsatellite markers used, and a National Cancer Institute workshop has recommended the use of a reference panel of two mononucleotide markers (BAT25, BAT26) and three dinucleotide markers (D5S346, D2S123, and D17S250). ${ }^{24}$ The distinction between MSI-L and MS-S tumours can only be accomplished if a greater number of markers are utilised. A unique pathological phenotype is identified for MSI-H

Abbreviations: $C R C$, colorectal cancer; $H D$, heteroduplex analysis; $h M L H 1$, mutator L homologue gene ( $h=$ human), HNPCC gene; hMSH2, mutator S homologue gene 2 ( $h=$ human) HNPCC gene; hMSH6, mutator $\mathrm{S}$ homologue gene 6 ( $\mathrm{h}$ =human) HNPCC gene; HNPCC, hereditary non-polyposis colorectal cancer; hPMS 1-2, human homologue of yeast postmeiotic segregation genes 1 and 2; ICG-HNPCC, International Collaborative Group for HNPCC; IHC, immunohistochemistry; MMR, mismatch repair; $\mathrm{MSI}$, microsatellite instability; $\mathrm{MSI}-\mathrm{H}$, high microsatellite instability; MSI-L, low microsatellite instability; MS-S, stable microsatellites; PCR, polymerase chain reaction; SSCP, single stranded conformational polymorphism. 
Table 1 Clinical criteria for suspected hereditary non-polyposis colorectal cancer (HNPCC) designed by study group

(1) Amsterdam criteria I

(2) Amsterdam criteria II

(3) Amsterdam criteria I or II on extended pedigree

(4) Amsterdam criteria including other HNPCC related cancers stomach, biliary tract, urinary tract, ovary, pancreas, abdominal cancer)

(5) Amsterdam criteria I except that the youngest case of CRC was 50-55 years at the time of diagnosis

(6) Patients aged 40 years or younger with at least one CRC among family members

(7) Both proband and one first degree relative had CRC before the age of 55 years

Familes from categories 1-3 meet the clinical criteria for HNPCC proposed by the International Collaborative Group for HNPCC. CRC, colorectal cancer.

tumours, while MSI-L/MS-S tumours appear to be phenotypically similar. ${ }^{24}$ However, the relatively high incidence of MSH6 germline mutations in suspected HNPCC families with MSH-L tumours indicates that MSI-L tumours should be accepted as evidence of MSI. It has been suggested that MSI in multiple tumours from the same family should be accepted as diagnostic criteria for HNPCC. ${ }^{27}$ However, MSI is not in itself proof of HNPCC as $10-20 \%$ of sporadic tumours also show some degree of MSI. ${ }^{29}$

This study was conducted to estimate the proportion of HNPCC among non-selected Danish CRC patients by using the family history approach, followed by genetic testing in all families suspected of having HNPCC based on family history. We screened for mutations in hMLHI and hMSH2 using single strand conformational polymorphism (SSCP) and heteroduplex (HD) analysis, and performed MSI analysis in suspected HNPCC families. This approach has not previously been used in a large prospective population based study on consecutive CRC patients $(n=1200)$ from a well defined area.

HNPCC is a poorly defined condition, and the diagnosis can be made using clinical criteria (family history) and/or results from tests at the molecular level. However, there is overlap but not full concordance between these two different ways of diagnosing the syndrome. In the evaluation of the frequency of HNPCC, we chose to categorise HNPCC patients using the following criteria.

(1) Patients who belonged to a family that met the Amsterdam criteria I or II (categories 1-3; table 1) and/or

(2) Patients who met less strict criteria for suspected HNPCC (categories 4-7; table 1) with pathogenic hMLHl/hMSH2 germline mutations.

\section{METHODS}

The study was designed as a prospective population based multicentre study and was approved by the regional ethics committee. All Danish patients living in a participating county diagnosed with primary CRC during the study period completed a questionnaire covering malignancies and age at onset of cancer among family members. Four Danish counties (counties of Aarhus, Ribe, Ringkoebing, and Viborg) with a total population of 1350000 people (26\% of the Danish population) were successively included in the period from November 1995 to October 1998. All CRC patients in Denmark are diagnosed and treated in the public health care system, which means that all CRC patients diagnosed within the area were identified. Patients were identified by the five institutes of pathology covering the area. When the pathologist diagnosed a patient with CRC, the HNPCC study group received the histology report at the same time as the local surgical department. Hence the study group was able to remind the surgical department to complete the questionnaires every time a patient met the inclusion criteria. The databases of the institutes of pathology were checked regularly to make sure that no patients were missed. The four counties have 16 hospitals with surgical departments treating CRC patients. All 16 surgical departments in the study area participated in the study. If a family met criteria for suspected HNPCC (table 1), blood samples were collected for screening for hMSH2 or hMLHl gene mutations, and tumour tissue samples were analysed for MSI. Exact 95\% confidence limits were calculated from binomial distribution.

\section{The questionnaire}

Patients were interviewed by surgeons who completed a questionnaire covering malignancies and age at onset of cancer among first degree relatives (parents, siblings, and children). We asked separately about cancer status, location of cancer, and age at the time of diagnosis among first degree relatives (parents, siblings, and children). If CRC was reported, second degree relatives were covered also (grandparents, parents' siblings, siblings' children, and grandchildren). Patients diagnosed before the age of 50 years and patients who reported a HNPCC related cancer among first degree relatives diagnosed before the age of 50 years were asked about malignancy among both first and second degree relatives. All types of cancers were registered, and the doctors who completed the questionnaires were instructed to ask specifically about primary location.

\section{Classification of family history}

Seven criteria were considered when evaluating suspected HNPCC (table 1). In all cases where the patient reported gastrointestinal cancer or cancer of the urinary tract among first degree relatives, the diagnosis was verified or rejected by checking hospital files, death certificates, or information from the Danish Cancer Registry. The family history was further explored on the slightest suspicion of HNPCC, even if criteria 1-7 in table 1 were not reported during the first interview. Patients from families that met the Amsterdam criteria I or II (categories 1-3; table 1) were classified as HNPCC patients. Patients from families that met less strict criteria for suspected HNPCC (categories 4-7; table 1) were classified as HNPCC patients if a pathogenic hMLHl or hMSH2 mutation was detected.

\section{Identification of family members}

A total of 1200 pedigrees were constructed using patient information from the questionnaire. We made an extra effort to identify all family members with HNPCC related cancers if the family history raised suspicion of HNPCC. If the patient was unable to identify family members, we sought to identify the relative through registers. Denmark has a long tradition of registration of the population. For example, death certificates of all Danish citizens who died since 1878 are available for researchers. Furthermore, a population register was established in 1924, and since 1968 all Danish inhabitants have been identified by a unique personal identity number, which is used as key ID in most registration systems, including the Danish Cancer Registry.

\section{Verification of diagnosis}

Successfully identified family members' hospital files and/or autopsy reports were recovered. If the file was not available at the hospital, information was obtained from the Danish Cancer Registry, which was founded in May 1942 and whose accuracy and completeness in terms of data registration lies in the range $95-97 \% .^{30}$ If the Danish Cancer Registry had no information on the family member, the death certificate was obtained. 


\section{Detection of mutations}

Blood samples from patients belonging to families who met the criteria for suspected HNPCC (categories 1-7; table 1) were screened for hMLHl and hMSH2 mutations using SSCP and HD analysis. We have previously shown that the combination of SSCP and HD is highly sensitive for the detection of hMLHl/hMSH2 mutations. ${ }^{31}$

The 35 coding exons of hMLH 1 and hMSH2 were amplified from purified DNA. Fluorescent 5'-labelled primers were used for SSCP/HD analysis. The labels were HEX or TET for the sense primers, and FAM or TAMRA for the antisense primers. Unlabelled cartridge purified scan primers were used for sequencing. Primers (Hobolth DNA syntese, Copenhagen, Denmark) were constructed using the "Oligo" programme from Medprobe AS (Oslo, Norway). The primers included part of the introns to detect possible splice mutations. Primer sequences are available from the authors on request. In order to keep the length of the polymerase chain reaction (PCR) products for SSCP below 300 base pairs, hMLH1 exon 12, and hMSH2 exons 3, 12, and 14 were divided into two overlapping segments, giving a total of 39 PCR products. These products were subjected to $\mathrm{HD}$ formation by placing them in a container with water at $100^{\circ} \mathrm{C}$ which was allowed to cool to $40^{\circ} \mathrm{C}$ over a period of 90 minutes. The PCR products were kept at $-20^{\circ} \mathrm{C}$ until SSCP/HD analysis which was performed at a fixed gel temperature of $20^{\circ} \mathrm{C}$. Variations in the SSCP/HD patterns led to sequencing of the exon in question. hMLHl exons 8 and 15, and hMSH2 exons 10 and 12 were sequenced without prior screening as these PCR products contain frequent polymorphisms. Sequencing was performed on PCR products with BigDye Terminator Cycle Sequencing Ready Reaction kits (Perkin Elmer) using standard conditions and the same sequencing primers as used for PCR. The PCR products were sequenced in both sense and antisense directions. SSCP, HD, and sequencing were performed on an ABI prism 377 sequencer, and were analysed using the software programs GeneScan, Sequence Analysis, and Sequence Navigator (PE Applied Biosystems).

\section{Microsatellite analysis}

DNA was extracted from fresh frozen tumour tissue and from the normal resection border. The extraction procedure was performed according to the manufacturer's protocol (PureGene D-5000 isolation kit; Biotech Line, Minneapolis, Minnesota, USA). Microdissection was performed to enrich for tumour cells, and the tumour cell content ranged from $50 \%$ to $100 \%$. In patients who met our criteria for suspected HNPCC (categories 1-7; table 1), we examined five loci containing mononucleotide and dinucleotide repeats: BAT26, D2S119, D3S1612, D5S404, and D17S261. PCR products were electrophoresed for three hours in an ABI Prism 377 sequencer. Data were collected in the GeneScan program for fragment analysis. We detected alterations in the microsatellites in the form of changes in the size of DNA strands by comparing tumour DNA and normal DNA in neighbouring lanes. MSI was scored as MSI-high (MSI-H) with two or more novel bands, MSI-low (MSI-L) with one novel band, and MS-stable (MS-S) when no novel bands appeared.

With the exception of BAT26, our markers differ from those recommended by the National Cancer Institute. ${ }^{24}$ With the purpose of testing the sensitivity of our markers, 50 probands were subjected to MSI analysis. These probands were selected randomly but with two restrictions: (1) they should have at least six first degree relatives, and (2) none of the relatives had developed cancer. We also compared our markers with the National Cancer Institute panel markers in 10 patients who met the Amsterdam criteria I.

\section{RESULTS}

A total of 1514 patients were diagnosed with primary CRC in the study period. Median age at the time of diagnosis was 71 years (range 19-95). We excluded 116 patients (7.7\%) due to severe illness or death shortly after diagnosis (median survival time after diagnosis was six days). Additionally, 70 patients $(4.6 \%)$ were excluded for ethical or psychological reasons (depression, psychosis, senility, or mental retardation). Among 1328 eligible patients, 1200 (90.4\%) completed the questionnaire. The remaining 128 patients (9.6\%) did not fill in the questionnaire as 51 patients $(3.8 \%)$ did not want to participate and 77 patients $(5.8 \%)$ were missed.

\section{Family history}

In total, 45 probands $(3.8 \%$ (95\% confidence interval (CI) $2.75-4.83 \%)$ ) from 42 families met the criteria for suspected HNPCC created by the study group. Probands from families who met the criteria for suspected HNPCC were divided into seven categories (categories $1-7$ in tables 1 and 2). All family histories were verified by histology, hospital files, the Danish Cancer Registry, and/or death certificates.

In categories 1,2 , and/or 3, 18 probands $(1.5 \%)$ from 16 families belonged to a family who met the Amsterdam criteria I or II (95\% CI $0.8-2.25 \%$ ). One of the probands (patient No 18 in table 2) met the Amsterdam criteria I only on extended pedigree, and in another two probands the third histologically verified adenocarcinoma that was needed for the families to satisfy the Amsterdam criteria I was only presumed to be colon cancer by pathologists (patient Nos 10 and 11 ). For all practical purposes, category 1,2, and 3 families met the clinical criteria for HNPCC proposed by the ICG-HNPCC. We therefore categorised these families as HNPCC families in the estimation of the frequency of HNPCC.

In categories $4-7$, a total of 27 cases (2.3\%) from 26 families were suspected of having HNPCC without meeting the Amsterdam criteria I or II (tables 1 and 2). Patients from families who belonged to categories 4-7 were not categorised as HNPCC patients in the estimation of the frequency of HNPCC unless a pathogenic hMLHI/hMSH2 mutation was detected.

\section{Mutation detection}

Blood samples for mutation analysis were collected from 41 of 45 HNPCC suspected patients $(91.1 \%)$. In the four missing cases, the patient died before blood samples were collected. Blood samples were analysed for mutations in hMSH2 or hMLHl for all 18 patients who belonged to a family meeting the Amsterdam criteria I or II, or Amsterdam criteria I or II on extended pedigree (categories 1-3; table 1). Blood samples were analysed in 23 of the 27 patients meeting our less stringent criteria (85.2\%) (categories 4-7; table 1 ).

Results of genetic testing are listed in tables 2 and 3. Pathogenic mutations were detected in 10 patients $(0.8 \%$ (95\% CI $0.3-1.4 \%)$ ) of whom eight ( $80 \%)$ satisfied the Amsterdam criteria I or II. Germline mutations were detected in only two of 23 patients $(8.7 \%)$ who met our less strict criteria for suspected HNPCC (categories 4-7). Among the 18 probands who belonged to categories 1-3 (Amsterdam criteria I or II), eight cases (44\% (95\% CI 22-67\%)) harboured hMLHl/ hMSH2 germline mutations.

In family No 1, two probands harboured a deletion in hMLHl in exon 11 of a G at base number 1046, codon 349, which created a frameshift mutation that produced a stop codon (table 3). In family No 2, an inframe deletion of hMLH1, exon 16 with a deletion of AAG at base number 1846-1848 at codon 616, created a deletion of Lys. This mutation has previously been published by seven authors. ${ }^{23}{ }^{26}{ }^{32-36}$ In family Nos 3 , 12,28 , and 39 , we detected an inframe mutation in hMSH2 (deletion of AAT), base number 1786-1788, codon 596, exon 12, causing a deletion of Asn. This mutation is probably pathogenic and has previously been published by several authors. ${ }^{23}{ }^{26}{ }^{37-39}$ In family No 4, a splice mutation $(\mathrm{T}>\mathrm{A})$ in hMSH2 was detected in exon 11, two bases downstream. This 
Table 2 Families listed according to fulfilment of clinical criteria for suspected hereditary non-polyposis colorectal cancer (HNPCC)

\begin{tabular}{|c|c|c|c|c|c|c|c|c|c|}
\hline $\begin{array}{l}\text { Patient } \\
\text { No }\end{array}$ & Family No & $\begin{array}{l}\text { Analysed for } \\
\text { MLH1 or } \\
\text { MSH2 } \\
\text { mutation }\end{array}$ & $\begin{array}{l}\text { Mutation } \\
\text { detected }\end{array}$ & $\begin{array}{l}\text { Multiple HNPCC } \\
\text { related cancers in at } \\
\text { least one family } \\
\text { member }\end{array}$ & $\begin{array}{l}\text { No of right } \\
\text { sided CRC in } \\
\text { the family }\end{array}$ & $\begin{array}{l}\text { MSI (our } \\
\text { selected } \\
\text { markers) }\end{array}$ & $\begin{array}{l}\mathrm{MSI}(\mathrm{NCl} \\
\text { reference } \\
\text { panel) }\end{array}$ & $\begin{array}{l}\text { Proband age at } \\
\text { time of CRC } \\
\text { diagnosis (y) }\end{array}$ & $\begin{array}{l}\text { Categorised as } \\
\text { HNPCC* }\end{array}$ \\
\hline \multicolumn{10}{|c|}{ Category 1-Amsterdam criteria I } \\
\hline 1 & 1 & Yes & MLHI & Yes & 5 & MSI-H & MSI-H & 39,52 & + \\
\hline 2 & 1 & Yes & MLHI & Yes & 5 & MSI-H & MSI-H & 28 & + \\
\hline 3 & 2 & Yes & MLHI & Yes & 3 & MSI-H & MSI-H & 49 & + \\
\hline 4 & 3 & Yes & $\mathrm{MSH} 2$ & Yes & 5 & MSI-H & MSI-H & $35,72,75$ & + \\
\hline 5 & 4 & Yes & $\mathrm{MSH} 2$ & Yes & 2 & MSI-H & MSI-L & $65+\operatorname{En} 55$ & + \\
\hline 6 & 5 & Yes & No & No & 0 & $\dagger$ & na & 38 & + \\
\hline 7 & 6 & Yes & No & No & 0 & MSI-H & MS-S & 60 & + \\
\hline 8 & 7 & Yes & No & No & 0 & MSI-H & MS-S & 42 & + \\
\hline 9 & 8 & Yes & No & No & 1 & MS-S & MS-S & 57 & + \\
\hline 10 & 9 & Yes & No & No & 0 & MS-S & MS-S & 44 & + \\
\hline 11 & 10 & Yes & No & No & 1 & MS-S & MSI-H & 45 & + \\
\hline \multicolumn{10}{|c|}{ Category 2-Amsterdam criteria II } \\
\hline 12 & 11 & Yes & MLHI & Yes & 3 & MSI-H & & 38,54 & + \\
\hline 13 & 12 & Yes & $\mathrm{MSH} 2$ & Yes & 1 & MSI-H & & 43 & + \\
\hline 14 & 13 & Yes & No & No & 0 & MSI-L & & 70 & + \\
\hline 15 & 14 & Yes & No & No & 0 & MS-S & & 31 & + \\
\hline 16 & 4 & Yes & $\mathrm{MSH} 2$ & Yes & 2 & MSI-H & & 36,58 & + \\
\hline 17 & 15 & Yes & No & No & 0 & MS-S & & 49 & + \\
\hline \multicolumn{10}{|c|}{ Category 3-Amsterdam criteria I or II on extended pedigree } \\
\hline 18 & 16 & Yes & No & Yes & 2 & MS-S & & $46,46,46$ & + \\
\hline \multicolumn{10}{|c|}{ Category 4-Amsterdam criteria including other HNPCC related cancer } \\
\hline 19 & 17 & Yes & No & No & 2 & MS-S & & 76 & \\
\hline 20 & 18 & Yes & No & No & 0 & MS-S & & 82 & \\
\hline 21 & 19 & Yes & No & No & 0 & MS-S & & 47 & \\
\hline 22 & 20 & Yes & No & No & 1 & MSI-H & & 70 & \\
\hline 23 & 21 & Yes & No & No & 0 & $\dagger$ & & 81 & \\
\hline 24 & 22 & Yes & No & No & 0 & $\dagger$ & & 34 & \\
\hline 25 & 23 & Yes & No & No & 1 & $\dagger$ & & 72 & \\
\hline 26 & 24 & Yes & No & No & 0 & MS-S & & 75 & \\
\hline 27 & 25 & Yes & No & Yes & 0 & MS-S & & 39,62 & \\
\hline 28 & 26 & Yes & No & Yes & 0 & MSI-L & & 49,52 & \\
\hline 29 & 26 & No & na & Yes & 0 & MS-S & & 81 & \\
\hline 30 & 27 & No & na & Yes & 0 & MS-S & & 73 & \\
\hline \multicolumn{10}{|c|}{ Category 5-Amsterdam criteria I (youngest family member with CRC 50-55 y at the time of diagnosis) } \\
\hline 31 & 28 & Yes & No & Yes & 0 & MS-S & & 52,52 & \\
\hline 32 & 29 & Yes & No & No & 0 & MS-S & & 52 & \\
\hline 33 & 30 & Yes & No & No & 0 & MS-S & & 56 & \\
\hline 34 & 31 & Yes & No & No & 1 & MS-S & & 81 & \\
\hline 35 & 32 & Yes & No & No & 1 & $\dagger$ & & 81 & \\
\hline 36 & 33 & No & na & No & 0 & MS-S & & 58 & \\
\hline \multicolumn{10}{|c|}{ Category 6-proband at age 40 y or younger with at least one CRC among family members } \\
\hline 37 & 34 & Yes & $\mathrm{MSH} 2$ & No & 0 & MSI-H & & 26 & + \\
\hline 38 & 35 & Yes & No & No & 0 & $\dagger$ & & 34 & \\
\hline 39 & 36 & Yes & No & No & 0 & MS-S & & 19 & \\
\hline 40 & 37 & Yes & No & No & 0 & MS-S & & 40 & \\
\hline 41 & 38 & Yes & No & No & 0 & MS-S & & 34 & \\
\hline \multicolumn{10}{|c|}{ Category 7 -both proband and one first degree relative with $C R C<55$ y } \\
\hline 42 & 39 & Yes & MSH2 & No & 1 & MSI-H & & 52 & + \\
\hline 43 & 40 & Yes & No & No & 1 & MS-S & & 53 & \\
\hline 44 & 41 & Yes & No & No & 0 & MS-S & & 49 & \\
\hline 45 & 42 & No & $\mathrm{na}$ & No & 1 & MS-S & & 49 & \\
\hline
\end{tabular}

†Amplification of tumour DNA not possible.

*Families from categories 1-3 meet the International Collaborative Group for HNPCC clinical criteria for HNPCC, and we categorised these families as HNPCC. Families from categories 4-7 were categorised as HNPCC only if hMLH1/hMSH2 mutations were detected.

En, endometrial cancer; na, not analysed; MSI, microsatellite instability; MSI-H, high microsatellite instability; MSI-L, low microsatellite instability; MS-S, stable microsatellites; CRC, colorectal cancer.

type of mutation is usually pathogenic, and three of three tested family members with CRC harboured this mutation. In family No 11, a hMLHl mutation $C>G$, base number 76 , codon 26, exon 1, created a Gln>stop.

In one of five cases diagnosed before the age of 40 years and with CRC among family members, a mutation was detected in hMSH2 (family No 28; tables 2 and 3). In one of four cases where both the proband and a first degree relative developed CRC before the age of 55 years (family No 39; tables 2 and 3), a mutation in hMSH2 was detected. In six cases who met the Amsterdam criteria I, except for the fact that the age limit for the youngest family member with CRC was 50-55 years (patient Nos 38-43; table 2), no mutations were detected, and none of the 12 cases who met the Amsterdam criteria if stomach, biliary tract, urinary tract, ovary, and pancreas cancer were included (patient Nos 19-30; table 2) harboured hMSH2 or hMLHl mutations.

Six of 16 families who met the Amsterdam criteria I or II presented with more than one right sided colon cancer cases among family members (table 2 ). Mutations were detected in five of these families (83\%). The remaining 10 families had only one or no right sided colon cancer cases among family members, and hMLH1 or hMSH2 mutations were detected in only one case ( $10 \%$ ) (Fisher's exact test, $2 p=0.0076)$. Seven of 16 families who met the Amsterdam criteria I or II presented with at least one family member with multiple HNPCC related 
Table 3 Hereditary non-polyposis colorectal cancer (HNPCC) suspected families with mutation in hMLH1 or hMSH2

\begin{tabular}{|c|c|c|c|c|c|c|c|c|c|c|}
\hline Category & $\begin{array}{l}\text { Patient } \\
\text { No }\end{array}$ & $\begin{array}{l}\text { Family } \\
\text { No }\end{array}$ & Gene & Exon & Base change & Base No & Codon & AA change & MSI & Comment \\
\hline $\begin{array}{l}\text { Amsterdam } \\
\text { criteria I }\end{array}$ & $\begin{array}{l}1 \\
2 \\
3 \\
4 \\
5\end{array}$ & $\begin{array}{l}1 \\
1 \\
2 \\
3 \\
4\end{array}$ & $\begin{array}{l}\text { MLH1 } \\
\text { MLH1 } \\
\text { MLH1 } \\
\text { MSH2 } \\
\text { MSH2 }\end{array}$ & $\begin{array}{l}11 \\
11 \\
16 \\
12 \\
11\end{array}$ & $\begin{array}{l}\text { Del G } \\
\text { Del G } \\
\text { Del AAG } \\
\text { Del AAT } \\
\text { T>A }\end{array}$ & $\begin{array}{l}1046 \\
1046 \\
1846-8 \\
1786-8 \\
2 \text { bases downstream }\end{array}$ & $\begin{array}{l}349 \\
349 \\
616 \\
596 \\
-\end{array}$ & $\begin{array}{l}\text { Frameshift } \\
\text { Frameshift } \\
\text { Del Lys } \\
\text { Del Asn } \\
\text { Splice mutation }\end{array}$ & $\begin{array}{l}\text { MSI-H } \\
\text { MSI-H } \\
\text { MSI-H } \\
\text { MSI-H } \\
\text { MSI-H }\end{array}$ & $\begin{array}{l}\text { Stop codon } 380 \\
\text { Stop codon } 380 \\
\text { Pathogenic, see text } \\
\text { Pathogenic, see text } \\
\text { Pathogenic, see text }\end{array}$ \\
\hline $\begin{array}{l}2 \\
\text { Amsterdam } \\
\text { criteria II }\end{array}$ & $\begin{array}{l}12 \\
13 \\
16\end{array}$ & $\begin{array}{l}11 \\
12 \\
4\end{array}$ & $\begin{array}{l}\text { MLH1 } \\
\text { MSH2 } \\
\text { MSH2 }\end{array}$ & $\begin{array}{r}1 \\
12 \\
11\end{array}$ & $\begin{array}{l}C>T \\
\text { Del AAT } \\
T>A\end{array}$ & $\begin{array}{l}76 \\
1786-8 \\
2 \text { bases downstream }\end{array}$ & $\begin{array}{r}26 \\
596 \\
-\end{array}$ & $\begin{array}{l}\text { Gln>stop } \\
\text { Del Asn } \\
\text { Splice mutation }\end{array}$ & $\begin{array}{l}\text { MSI-H } \\
\text { MSI-H } \\
\text { MSI-H }\end{array}$ & $\begin{array}{l}\text { Stop codon } \\
\text { Pathogenic, see text } \\
\text { Pathogenic, see text }\end{array}$ \\
\hline $\begin{array}{l}6 * \\
7^{*}\end{array}$ & $\begin{array}{l}37 \\
42\end{array}$ & $\begin{array}{l}34 \\
39\end{array}$ & $\begin{array}{l}\mathrm{MSH} 2 \\
\mathrm{MSH} 2\end{array}$ & $\begin{array}{l}12 \\
12\end{array}$ & $\begin{array}{l}\text { Del AAT } \\
\text { Del AAT }\end{array}$ & $\begin{array}{l}1786-8 \\
1786-8\end{array}$ & $\begin{array}{l}596 \\
596\end{array}$ & $\begin{array}{l}\text { Del Asn } \\
\text { Del Asn }\end{array}$ & $\begin{array}{l}\text { MSI-H } \\
\text { MSI-H }\end{array}$ & $\begin{array}{l}\text { Pathogenic, see text } \\
\text { Pathogenic, see text }\end{array}$ \\
\hline
\end{tabular}

${ }^{*}$ Category 6, proband at age 40 years or younger with at least one CRC among family members; category 7 , both proband and one first degree relative with CRC $<55$ years.

MSI, microsatellite instability; MSI-H, high microsatellite instability; MSI-L, low microsatellite instability; MS-S, stable microsatellites; CRC, colorectal cancer

cancers (table 2). Mutations were detected in six of these families (86\%). Mutations were not detected among any of the nine probands without multiple HNPCC related cancers among relatives (Fisher's exact test, $2 \mathrm{p}=0.0009$ ).

\section{Microsatellite instability}

Analysis of MSI was performed on 39 of 45 suspected HNPCC patients $(86.7 \%)$ using our markers (BAT26, D2S119, D3S1612, D5S404 and D17S261). In six cases DNA amplification was not possible due to poor tissue quality. In 24 cases the tumours were MS-S, in two cases MSH-L, and in 13 cases MSI-H (table 2).

Mutations in hMLH1 or hMSH2 were detected in 10 of 15 MSI-H or MSI-L tumours (positive predictive value $66.7 \%$ among suspected HNPCC patients). Germline mutations were exclusively detected among families who showed MSI-H and therefore in terms of identifying hMLHl and hMSH2 mutations, MSI analysis showed a sensitivity of $100 \%$.

Seven of 18 patients (39\%) who met the Amsterdam criteria I or II did not show MSI-H or MSI-L. MS-S was present in six of these cases and in one case no DNA amplification was possible due to poor tissue quality. Hence the sensitivity of MSI analysis in terms of identifying families who met the Amsterdam criteria I or II was $61 \%$ ( 11 of 18 cases). Among 27 suspected HNPCC patients who did not meet the Amsterdam criteria I or II (patient Nos 19-45; table 2), only four (14.8\%) showed MSI-H or MSI-L in tumour tissue.

With the purpose of testing our microsatellite markers, 50 patients without a family history of cancer were subjected to MSI analysis. MSI-H was observed in seven cases (14\%). Other laboratories have demonstrated a frequency of microsatellite instability between $10 \%$ and $20 \%$ among sporadic CRC cases. ${ }^{29}{ }^{40-42}$ Hence our results are comparable with results from other series.

We also compared our markers with the National Cancer Institute panel markers (BAT25, BAT26, D5S346, D2S123, and D17S250) in 10 patients who met the Amsterdam criteria I. In a test performed on 10 patients meeting the Amsterdam criteria I, our markers showed MSI-H in seven cases and MS-S in three cases. The National Cancer Institute panel markers showed MSI-H in five cases, MSI-L in one case, and MS-S in four cases (table 2). Germline mutations in hMLHI/hMSH2 were detected in five cases, and both our panel and the National Cancer Institute panel showed MSI in all cases. However, in one case the National Cancer Institute panel showed MSI-L in a gene carrier (patient No 6). Although the number of patients tested was limited, our panel appeared to be at least as sensitive as the markers recommended by the National Cancer Institute in terms of MSI detection.

HNPCC was detected in 13 cases ( $1.1 \%$ ) if the diagnosis was restricted to patients from Amsterdam criteria I or II families with MSI-H or MSI-L tumours, and/or families with pathogenic mutations in hMLH1 or hMSH2.

\section{DISCUSSION}

This is the first prospective population based study on a large series of consecutive CRC patients $(n=1200)$ where a family history of malignancy was obtained and suspected HNPCC cases were screened for hMLHl and hMSH2 mutations and subjected to MSI analysis. In the evaluation of the frequency of HNPCC, we chose to categorise patients as HNPCC if they belonged to a family that met the Amsterdam criteria I or II and/or met less strict criteria for suspected HNPCC (categories 4-7; table 1) with pathogenic hMLH1/hMSH2 germline mutations.

We identified 45 probands $(3.8 \%)$ presenting with a suspected HNPCC family history. Among these, 18 cases ( $1.5 \%$ (95\% CI $0.8-2.25 \%)$ ) belonged to a family that met the Amsterdam criteria I or II. In another two cases who met the criteria for suspected HNPCC without meeting the Amsterdam criteria I or II, hMLH1/hMSH2 germline mutations were detected. Hence HNPCC were diagnosed in 20 cases, which corresponds to a frequency of HNPCC of $1.7 \%$ (95\% CI $1.0-2.4 \%)$. Among patients younger than 50 years of age at the time of diagnosis, $14.3 \%$ (11/77 cases) were categorised as HNPCC patients.

Several study groups have estimated the frequency of HNPCC among consecutive CRC patients based on family history but without testing for hMLHl/hMSH2 germline mutations. In a prospective multicentre study from 10 Finnish hospitals, Mecklin et al found that the frequency of families meeting the Amsterdam criteria I was $0.7 \%$, and $1.7 \%$ were suspected of HNPCC using less strict criteria. ${ }^{43}$ Evans and colleagues ${ }^{44}$ studied 1137 consecutive CRC patients in a partly retrospective (663 patients), partly prospective (474 patients) study. Three cases $(0.3 \%)$ met the Amsterdam criteria I, and a total of $1.4 \%$ fulfilled less strict criteria for HNPCC. Ponz et al estimated the frequency of HNPCC among CRC cases to be $3.4-4.5 \%$ in Northern Italy. ${ }^{45}$ In our study, a total of 11 cases $(0.9 \%)$ met the Amsterdam criteria I. Thus estimation of the frequency of HNPCC based entirely on the Amsterdam criteria I shows different results in different populations. In a recent Italian study, Cornaggia et al demonstrated a very low frequency of HNPCC $(0.5 \%)$ in two areas belonging to the Lombardy Cancer Registry compared with other areas of Italy ${ }^{46}$ Differences in the frequency of HNPCC between populations probably reflect actual population differences but may also reflect differences in the ability of verifying diagnoses among family members and differences in the level of proof that is accepted to verify diagnosis. 
Another approach to estimating the frequency of HNPCC was demonstrated by Aaltonen et al in a study of 509 CRC patients. ${ }^{29}$ Tumour tissues were screened for DNA replication error, and leucocyte DNA from 63 patients with DNA replication error positive tumours (12\%) was screened for germline mutations in hMLHl and hMSH2. Ten patients $(2.0 \%)$ harboured germline mutations in hMLH1 or hMSH2. Nine of these patients had a first degree relative with CRC or endometrial cancer, four patients met the Amsterdam criteria I, and three met the Amsterdam criteria I on extended pedigree. In concordance with Aaltonens' MSI approach study, we found that $9 / 10$ patients $(90.0 \%)$ with mutations in hMLHl or hMSH2 had a first degree relative with CRC or endometrial cancer. However, we demonstrated that 39\% of the patients who met the Amsterdam criteria I or II did not show MSI-H or MSI-L. These cases would have been missed if patients with MS-S tumours were excluded from further investigation. Aaltonen et al did not identify any families who met the Amsterdam criteria I among patients with MS-S and MSI-L tumours. This may be explained by the fact that Aaltonen et al routinely only identified and verified diagnoses among first degree relatives. In the majority of our families who met the Amsterdam criteria I or II, a second degree relative was needed to fulfill the criteria. Another important factor may be that the lifetime risk of CRC in the background population is higher in Denmark than in Finland. ${ }^{47} 48$

Among the 39 probands suspected of having HNPCC who were subjected to MSI analysis, 13 probands had MSI-H tumours, and pathogenic hMLHl/hMSH2 mutations were detected in 10 of these probands (77\%). The Amsterdam criteria I or II were fulfilled in $8 / 10$ gene carriers $(80.0 \%)$. In none of the 24 suspected HNPCC patients with MS-S tumours were pathogenic hMLHl/hMSH2 mutations detected. In the two suspected HNPCC probands with MSI-L tumours, no hMLHl/ hMSH2 mutations were detected. However, MMR mutations (especially hMSH6 mutations) cannot be ruled out in these probands. ${ }^{28}$ Several laboratories have reported MSI-H in all MSI analysed patients with pathogenic hMLHI/hMSH2 mutations. ${ }^{22} 232526$ These results are in agreement with our findings as all patients with hMLH1/hMSH2 mutations in our study had MSI-H tumours using our panel of markers. It is likely that the majority of patients who meet the Amsterdam criteria I or II without MSI harbour mutations in other MMR genes or have other hereditary cancer syndromes, and surveillance is recommended.

Using our criteria for suspected HNPCC (table 1), MSI analysis showed a sensitivity of 100\% (10 MSI tumours in 10 gene carriers). Among suspected HNPCC patients, MSI analysis showed a positive predictive value of $67 \%$ in terms of detecting hMLHl and hMSH2 mutations. Although the number of patients was limited in size ( 10 germline mutations out of 15 MSI-H or MSI-L tumours among 39 HNPCC suspected patients subjected to MSI analysis), it indicates that the technique is reliable. However, the sensitivity of MSI analysis was only $61 \%$ in terms of detecting families that satisfied the Amsterdam criteria I or II. Our results demonstrated that MSI analysis is very useful in detecting patients with hMLHl/hMSH2 mutations among patients who belong to families suspected of having HNPCC but of limited value as the first step in the identification of Amsterdam criteria I or II families.

It has been suggested that families with aggregation of CRC among family members who do not present with the MSI phenotype may represent chance familial clusterings, the effect of shared environmental carcinogens, or the effect of a different genetic pathophysiology, perhaps involving genes not involved in mismatch repair. ${ }^{26}$ In this study, the HNPCC ratio declined to $1.1 \%$ ( 13 cases) if we added the criterion of MSI-H or MSI-L as a restriction to the diagnosis.

Our results of genetic testing are in agreement with previous studies that showed a relatively high frequency of
hMLH1/hMSH2 mutations in Amsterdam criteria I or II families, and a low frequency in families who did not meet these criteria. ${ }^{99}$ However, the majority of hMLHI/hMSH2 gene carriers among consecutive CRC patients could have been identified among families who did not meet the Amsterdam criteria I or II if these families represented a large number compared with the number of Amsterdam criteria I or II families or if penetrance was lower than previously estimated. Families with HNPCC identified by us at the molecular level almost always presented with a massive occurrence of HNPCC related cancers among family members. Only two families did not fulfil the Amsterdam criteria I or II. In one of these cases, the proband was a 26 year old male who harboured a mutation in hMSH2 (family No 28; table 2). His mother, who also carried the mutation, had breast cancer at the age 53 years, his aunt had kidney cancer at the age of 64 years, and the grandfather developed myeloid leukaemia at the age 82 years and rectal cancer at age 83 . In the second case, the proband was a male diagnosed at the age of 52 years who harboured a mutation in hMSH2, and had a large mucinous cancer in the caecum (family No 39; table 2). His father developed colon cancer at the age of 52 years, and further exploration of the family history on the father's side was not possible. Hence in both cases the patients showed features of HNPCC, and both showed the MSI-H phenotype in tumour tissue. In another 21 tested cases, where the families were suspected of having HNPCC without meeting the Amsterdam criteria I or II, no hMLHl/hMSH2 mutations were detected. Among these 21 cases, 16 were successfully tested for MSI in the tumour tissue, and only one case showed the MSI-H phenotype. The proportion of MSI-H tumours among patients suspected of having HNPCC without meeting the Amsterdam criteria I or II was as low as $14.8 \%$, which corresponds to the frequency of MSI-H tumours among sporadic cases. These results suggest that the majority of these families are probably not genuine HNPCC families.

As families who meet the Amsterdam criteria I or II are likely to represent a hereditary CRC syndrome, the family history of cancer is still indispensable, and we find it interesting that only two of 20 cases who were categorised as HNPCC did not met the Amsterdam criteria I or II. Testing at the molecular level did not reveal a large number of families that would not have been identified on family history alone.

The derived estimate of the proportion of CRCs attributable to HNPCC (1.7\%) among consecutive CRC patients in this study can be criticised on several points. It may be an overestimate as we only detected hMLH1/hMSH2 germline mutations in 10 of $20(50 \%)$ patients categorised as HNPCC. Aggregation of HNPCC related cancers in mutation negative Amsterdam criteria I or II families is due in some cases to coincidental clustering or shared environmental carcinogens. We have calculated that it is likely that $25 \%$ of all Danish mutation negative families who meet the Amsterdam criteria I and where the proband was younger than 50 years of age, fulfil the criteria due to coincidental clustering of CRC among relatives. ${ }^{50}$ Moreover, among families who met the Amsterdam criteria I or II, synchronous or metachronous HNPCC related cancers among family members and several family members with right sided colon cancer seemed to be strong predictors of mutation detection. If these features were absent, mutations were rarely detected. It is therefore likely that the majority of families who met the Amsterdam criteria I or II with predominantly left sided CRC and/or without multiple HNPCC related cancers in any family members, fulfilled the criteria due to other causes than mutations in hMLHI or hMSH2. A large proportion of these families did not show MSI-H or MSI-L in tumour tissue, and may not represent families with an underlying hereditary MMR system defect.

However, it is probably more likely that the derived estimate $(1.7 \%)$ is an underestimate. A National Cancer Institute workshop in 1997 defined the Bethesda guidelines for testing 
for MSI in which much wider inclusion criteria were used.$^{51}$ The use of these guidelines would probably have increased the sensitivity. Moreover, due to competing causes of death and the small size of families, the most accurate way to determine the proportion of mutation positive CRCs would be to undertake MSI studies in all cases of CRC. Also, the minor genes hMSH6, hPMS1, and hPMS2 were not analysed, and our methods for mutation detection were not $100 \%$ sensitive. ${ }^{52}$ Some HNPCC families may have escaped identification due to lack of knowledge about cancer occurrence among family members. New mutants and non-paternity patients with HNPCC would, for example, not be detected. Patients harbouring low penetrance mutations would in many cases also be missed, and as approximately $10 \%$ of the carriers of known pathogenic mutations never develop cancer, it is possible that some cases (especially small families) are missed due to non-penetrant relatives. ${ }^{53}$ Another possible source of misinterpretation is that there may be phenocopies among the probands where the family has HNPCC but the analysed patient is a non-carrier and has developed cancer for reasons other than HNPCC.

We believe that our estimate is fairly accurate. The proportion of hMLHl/hMSH2 germline mutations among patients who met the Amsterdam criteria I in our study is comparable with the results from other laboratories (mutation detection rate $50 \% v 45 \%$ in our study), ${ }^{9}$ and $8 / 10$ carriers of hMLH1/hMSH2 mutations presented with a massive occurrence of HNPCC related cancers among family members.

Among families suspected of having HNPCC without meeting the Amsterdam criteria I or II, other study groups have demonstrated comparable or higher mutation detection rates $\left(8-28 \% v 9 \%\right.$ in our study). ${ }^{92}{ }^{29}$ However, for several reasons there may be differences between families from different study groups even when the same clinical criteria are used. In countries such as Denmark with almost complete and high quality cancer registration and high quality population registers, it is possible to verify or reject the family history in most cases and to explore further the family history for malignancy. In countries with a lower quality of registration, we would expect a higher proportion of mutation carriers among families who are incorrectly reported with weak family histories of HNPCC related cancers, simply because verification of family member diagnoses is impossible. Another aspect is the possibility of differences between families who are self referred to cancer clinics and those families who are identified on the doctor's initiative (as in our study). It is possible that self referred families are more likely to contain more extreme features such as multiple cancers or several family members diagnosed at an early age. A large proportion of our families who met our criteria for suspected HNPCC (categories 1-7; table 1) would probably not have been identified on the patient's initiative. Ours was a prospective population based study among non-selected CRC patients, while most other studies are not, and this may explain the low mutation detection rate among suspected HNPCC families who did not meet the Amsterdam criteria I or II. We believe that the low mutation detection rate among the suspected HNPCC patients who did not meet the Amsterdam criteria I or II makes it unlikely that a large number of mutation carriers were missed due to incomplete selection of families. Wijnen et al detected hMLH1/hMSH2 mutations in only three of 39 families (8\%) suspected of having HNPCC but not fulfilling the Amsterdam criteria $\mathrm{I}^{49}$ In one of these families, the third cancer was an endometrial cancer, hence fulfilling the Amsterdam criteria II, and in another the family history was not available as the rest of the family was residing in Indonesia. If these two cases are excluded, Wijnen et al detected hMLH1/hMSH2 mutations in only one of 37 cases $(2.7 \%)$ suspected of having HNPCC without meeting the Amsterdam criteria. Furthermore, hMLHl/ hMSH2 mutations are rarely detected in patients without a family history of HNPCC related cancers. In a study conducted by ICG-HNPCC, 50 CRC patients diagnosed before the age of 40 years were screened for mutations in hMLHl and hMSH2. Only three patients $(6 \%)$ harboured mutations. ${ }^{9}$ In our study, only 20 of 1514 patients (1.3\%) were diagnosed before the age of 40 years, of whom eight probands (40\%) were suspected of having HNPCC according to our criteria for suspected HNPCC. Using the IGC-HNPCC data on the remaining 12 patients, we would expect to find less than one patient $(0.06 \times 12=0.72)$ with an hMLH1/hMSH2 mutation among patients diagnosed before the age of 40 years without a family history of HNPCC related cancer. An exception may be extremely young CRC patients. Liu et al demonstrated germline mutations in five of 12 patients diagnosed before the age of 35 years with microsatellite instability. ${ }^{54}$ In this study, only 11 of 1514 patients $(0.7 \%)$ were diagnosed before the age of 35 years, and seven of these met our criteria for suspected HNPCC. Only two of these seven patients showed MSI-H, and both harboured germline mutations. For the above reasons we find it most likely that the low mutation detection rate among suspected HNPCC families who did not belong to categories $1-3(9 \%)$ is fairly accurate.

Immunohistochemical (IHC) analysis with antibody based screening for loss of expression of hMLHI and hMSH2 has recently been shown to have a high concordance with MSI analysis. Thus Marcus et al compared immunohistochemical patterns of $38 \mathrm{MSI}-\mathrm{H}$ tumours. They found that 37/38 MSI-H tumours (97.4\%) were predicted to have a MMR gene defect, as demonstrated by the absence of hMLHl and/or hMSH2 expression..$^{55}$ Cawkwell et al investigated 502 CRCs for MSI. They demonstrated that 66/66 MSI tumours (100\%) were associated with complete lack of expression of either hMLHl or HMSH2. ${ }^{56}$ The cost of IHC is much lower than that of MSI analysis, and it is likely that IHC combined with MSI analysis will be the pre-screen test of choice for HNPCC in the future.

It has previously been suggested that HNPCC accounts for $5-10 \%$ of all CRC cases. ${ }^{7}$ The present study shows that this is hardly the case. The Amsterdam criteria I or II were met in 18 patients $(1.5 \%(95 \%$ CI $0.8-2.25 \%))$. In another two patients $(0.2 \%)$ suspected of having HNPCC, without meeting the Amsterdam criteria I or II, pathogenic hMLHI/hMSH2 mutations were detected. Hence a total of 20 cases ( $1.7 \%$ (95\% CI $1.0-2.4 \%)$ ) were categorised as HNPCC patients.

Our study demonstrated that MSI analysis is very useful in detecting hMLHI/hMSH2 mutation carriers among patients who belong to a family suspected of having HNPCC. Using our criteria for suspected HNPCC, MSI analysis showed a sensitivity of $100 \%$ and, among suspected HNPCC patients, the positive predictive value was $67 \%$ in terms of detecting hMLHl and hMSH2 mutations. Although the number of patients was limited in size ( 10 germline mutations out of 13 MSI-H and two MSI-L tumours among 39 suspected HNPCC patients subjected to MSI analysis), our study demonstrates that the technique is reliable. We showed that the use of different markers (the National Cancer Institute panel compared with our panel) gives different results. However, both panels showed either MSI-H or MSI-L in all gene carriers, which suggests that MSI-L tumours should be accepted as a proof of MSI.

The sensitivity of MSI testing was only $61 \%$ in terms of detecting families that satisfied the Amsterdam criteria I or II, which in our opinion makes MSI analysis less appropriate as the first step in the identification of families suspected of having hereditary CRC. Families with MS-S tumours who meet the clinical criteria for HNPCC may not harbour defects in the MMR system. However, these families should still be considered high risk, and therefore the family history of cancer is still indispensable.

The most important novel finding in this study was that the majority of hMLHI/hMSH2 mutation carriers, identified among consecutive CRC patients, present with a very strong family history of HNPCC related cancers. The majority of HNPCC suspected families did not meet the Amsterdam criteria I or II, but germline mutations were detected in only $9 \%$ of 
the probands who were suspected of having HNPCC without meeting the Amsterdam criteria I or II. Hence we would not expect a large number of $\mathrm{hMLH} / \mathrm{hMSH} 2$ gene carriers among CRC patients with a weak family history of HNPCC related cancers.

\section{ACKNOWLEDGMENTS}

We gratefully acknowledge the efforts of our colleagues at the participating surgical departments and institutes of pathology for completing questionnaires, collecting tissue/blood samples, and filling in forms to describe the cancers. In particular we want to thank Dr Peter Rasmussen, Dr Niels Krarup, Dr Ole Brandsborg, Dr Peter Saksø, Dr Knud Jørgensen, Dr Claus Nepper Holm, Dr NO Jacobsen, Dr Flemming Melsen, Dr Helle Dybdahl, Dr Niels Ryegaard Rasmussen, Dr Anders Larsen, Dr Inger Marie Reintoft, Dr Mogens Rørbæk Madsen, Dr Erik Skoubo Kristensen, Dr Ivan Nørbæk Sørensen, Dr Asger Bisgaard Petersen, Dr Ebbe Fuglsang, Dr Max Vetner, Dr Jørn Nielsen, Dr Lausten-Thomsen, Dr Thor Knudsen, Dr Einar Holgersen, and Dr Vibeke Thue Nielsen. We are also very grateful to Professor Søren M Bentzen, Group for Biostatistics in Oncology, Gray Laboratory Cancer Research Trust, PO Box 100, Mount Vernon Hospital, Northwood, Middlesex, UK, and Dr Steffen Bülow, Hvidovre Hospital, Denmark for their contribution to this paper, and Dr Lone E Munk Sunde, Oncogenetic Clinic, Aarhus University Hospital, Denmark, for her support in the genetic counselling of the families. Financial support was received from "Karen Elise Jensen Foundation", Denmark, Institute of Experimental Clinical Research, Aarhus University, Denmark, "The Danish Cancer Society", "The Boel Foundation", Denmark, "Dansk Kraeftforsknings Foundation", Denmark, "Surgical Research Foundation"Randers Hospital, Denmark, "Snedkermester Sophus Jacobsen og hustru Astrid Jacobsen Foundation", Denmark, "Health Insurance Fond", Denmark, "Fritz, Georg and Marie Cecilie Gluds legat", Denmark, and "Aarhus Amtssygehus research Foundation", Denmark.

\section{Authors' affiliations}

N Katballe, S Laurberg, Surgical Research Unit 900, Department of Surgery L, Aarhus University Hospital, Aarhus Amtssygehus, Aarhus, Denmark

M Christensen, F P Wikman, T F Ørntoft, Department of Clinical Biochemistry, Aarhus University Hospital, Skejby Sygehus, Aarhus, Denmark

\section{REFERENCES}

1 Warthin AS. Heredity with reference to carcinoma as shown by the study of the cases examinated in the pathological laboratory of the University of Michigan. Arch Intern Med 1913;12:546-55

2 Lynch HT, Krush AJ. Cancer family "G" revisited: 1895-1970. Cancer 1971:27:1505-11.

3 Lynch HT, Kimberling W, Albano WA, et al. Hereditary nonpolyposis colorectal cancer (Lynch syndromes I and II). I. Clinical description of resource. Cancer 1985;56:934-8

4 Lynch HT, Lanspa SJ, Boman BM, et al. Hereditary nonpolyposis colorectal cancer-Lynch syndromes I and II. Gastroenterol Clin North Am 1988;17:679-712.

5 Lynch HT, Smyrk TC, Watson P, et al. Genetics, natural history, tumor spectrum, and pathology of hereditary nonpolyposis colorectal cancer: an updated review. Gastroenterology 1993;104:1535-49.

6 Watson P, Lynch HT. Extracolonic cancer in hereditary nonpolyposis colorectal cancer. Cancer 1993;71:677-85.

7 Vasen HF, Mecklin JP, Khan PM, et al. The International Collaborative Group on Hereditary Non-Polyposis Colorectal Cancer (ICG-HNPCC). Dis Colon Rectum 1991;34:424-5.

8 Vasen HF, Watson P, Mecklin JP, et al. New clinical criteria for hereditary nonpolyposis colorectal cancer (HNPCC, Lynch syndrome) proposed by the International Collaborative group on HNPCC. Gastroenterology 1999;116:1453-6.

9 Park JG, Vasen HF, Park KJ, et al. Suspected hereditary nonpolyposis colorectal cancer: International Collaborative Group on Hereditary Non-Polyposis Colorectal Cancer (ICG-HNPCC) criteria and results of genetic diagnosis. Dis Colon Rectum 1999;42:710-15.

10 Akiyama Y, Sato H, Yamada T, et al. Germ-line mutation of the hMSH6/GTBP gene in an atypical hereditary nonpolyposis colorectal cancer kindred. Cancer Res 1997:57:3920-3.

11 Bronner CE, Baker SM, Morrison PT, et al. Mutation in the DNA mismatch repair gene homologue $\mathrm{hMLHI}$ is associated with hereditary non-polyposis colon cancer. Nature 1994;368:258-61.

12 Fishel R, Lescoe MK, Rao MR, et al. The human mutator gene homolog $\mathrm{MSH} 2$ and its association with hereditary nonpolyposis colon cancer. Cell 1994;77:167.
13 Leach FS, Nicolaides NC, Papadopoulos N, et al. Mutations of a mutS homolog in hereditary nonpolyposis colorectal cancer. Cell 1993;75:1215-25

14 Miyaki M, Konishi M, Tanaka K, et al. Germline mutation of MSH6 as the cause of hereditary nonpolyposis colorectal cancer. Nat Genet 1997; 17:271-2.

15 Nicolaides NC, Papadopoulos N, Liu B, et al. Mutations of two PMS homologues in hereditary nonpolyposis colon cancer. Nature 1994;371:75-80

16 Papadopoulos N, Nicolaides NC, Wei YF, et al. Mutation of a mutL homolog in hereditary colon cancer. Science 1994;263:1625-9.

17 Peltomaki P, Vasen HF. Mutations predisposing to hereditary nonpolyposis colorectal cancer: database and results of a collaborative study. The International Collaborative Group on Hereditary Nonpolyposis Colorectal Cancer. Gastroenterology 1997;113:1146-58.

18 Viel A, Novella E, Genuardi M, et al. Lack of PMS2 gene-truncating mutations in patients with hereditary colorectal cancer. Int J Oncol 1998:13:565-9

19 Kolodner RD, Tytell JD, Schmeits JL, et al. Germ-line msh6 mutations in colorectal cancer families (in process citation). Cancer Res 1999:59:5068-74.

20 Planck $\mathbf{M}$, Koul A, Fernebro E, et al. hMLH1, hMSH2 and hMSH6 mutations in hereditary non-polyposis colorectal cancer families from southern Sweden. Int J Cancer 1999;83:197-202.

21 Aaltonen LA, Peltomaki P, Mecklin JP, et al. Replication errors in benign and malignant tumors from hereditary nonpolyposis colorectal cancer patients. Cancer Res 1994;54:1645-8.

22 Brown SR, Finan PJ, Cawkwell L, et al. Frequency of replication errors in colorectal cancer and their association with family history. Gut 1998;43:553-7.

23 Moslein G, Tester DJ, Lindor NM, et al. Microsatellite instability and mutation analysis of $\mathrm{hMSH} 2$ and $\mathrm{hMLH} 1$ in patients with sporadic familial and hereditary colorectal cancer. Hum Mol Genet 1996;5: 1245-52

24 Boland CR, Thibodeau SN, Hamilton SR, et al. A National Cancer Institute Workshop on Microsatellite Instability for cancer detection and familial predisposition: development of international criteria for the determination of microsatellite instability in colorectal cancer. Cancer Res 1998;58:5248-57

25 Lamberti C, Kruse R, Ruelfs C, et al. Microsatellite instability-a useful diagnostic tool to select patients at high risk for hereditary non-polyposis colorectal cancer: a study in different groups of patients with colorectal cancer. Gut 1999;44:839-43.

26 Liu B, Parsons R, Papadopoulos N, et al. Analysis of mismatch repair genes in hereditary non-polyposis colorectal cancer patients. Nat Med 1996;2: 169-74.

27 Jass JR. Towards a molecular classification of colorectal cancer (in process citation). Int J Colorectal Dis 1999;14:194-200.

28 Wu Y, Berends M, Mensink RG, et al. Association of hereditary nonpolyposis colorectal cancer-related tumors displaying low microsatellite instability with MSH6 germline mutations. Am J Hum Genet 1999:65:1291-8.

29 Aaltonen LA, Salovaara R, Kristo P, et al. Incidence of hereditary nonpolyposis colorectal cancer and the feasibility of molecular screening for the disease. N Engl J Med 1998;338:1481-7.

30 Parkin DM, Muir CS. Cancer incidence in five continents. Comparability and quality of data. IARC Sci Publ 1992;:45-173.

31 Wikman FP, Katballe N, Christensen M, et al. Efficient mutation detection in mismatch repair genes using a combination of single-strand conformational polymorphism and heteroduplex analysis at a controlled temperature. Genet Test 2000;4:15-21.

32 Farrington SM, Lin-Goerke J, Ling J, et al. Systematic analysis of hMSH2 and $\mathrm{hMLHI}$ in young colon cancer patients and controls. Am J Hum Genet 1998;63:749-59.

33 Wijnen J, Khan PM, Vasen $\mathrm{H}$, et al. Majority of hMLH1 mutations responsible for hereditary nonpolyposis colorectal cancer cluster at the exonic region 15-16. Am J Hum Genet 1996;58:300-7.

34 Viel A, Genuardi M, Capozzi E, et al. Characterization of MSH2 and $\mathrm{MLH} 1$ mutations in Italian families with hereditary nonpolyposis colorectal cancer. Genes Chromosomes Cancer 1997; 18:8-18.

35 Miyaki M, Konishi M, Muraoka M, et al. Germ line mutations of hMSH2 and $\mathrm{hMLH} I$ genes in Japanese families with hereditary nonpolyposis colorectal cancer (HNPCC): usefulness of DNA analysis for screening and diagnosis of HNPCC patients. J Mol Med 1995;73:515-20.

36 Hamilton SR, Liu B, Parsons RE, et al. The molecular basis of Turcot's syndrome. N Engl J Med 1995:332:839-47.

37 Buerstedde JM, Alday P, Torhorst J, et al. Detection of new mutations in six out of 10 Swiss HNPCC families by genomic sequencing of the hMSH2 and hMLH1 genes. J Med Genet 1995;32:909-12.

38 Borresen AL, Lothe RA, Meling $\mathrm{Gl}$, et al. Somatic mutations in the hMSH2 gene in microsatellite unstable colorectal carcinomas. Hum Mol Genet 1995;4:2065-72

39 Mary JL, Bishop T, Kolodner R, et al. Mutational analysis of the hMSH2 gene reveals a three base pair deletion in a family predisposed to colorectal cancer development. Hum Mol Genet 1994;3:2067-9.

40 Brassett C, Joyce JA, Froggatt NJ, et al. Microsatellite instability in early onset and familial colorectal cancer. J Med Genet 1996;33:981-5.

41 Jass JR, Do KA, Simms LA, et al. Morphology of sporadic colorecta cancer with DNA replication errors. Gut 1998;42:673-9.

42 Samowitz WS, Slattery ML, Kerber RA. Microsatellite instability in human colonic cancer is not a useful clinical indicator of familial colorectal cancer. Gastroenterology 1995;109:1765-71. 
43 Mecklin JP, Jarvinen HJ, Hakkiluoto A, et al. Frequency of hereditary nonpolyposis colorectal cancer. A prospective multicenter study in Finland. Dis Colon Rectum 1995;38:588-93.

44 Evans DG, Walsh S, Jeacock J, et al. Incidence of hereditary non-polyposis colorectal cancer in a population-based study of 1137 consecutive cases of colorectal cancer. Br J Surg 1997:84:1281-5.

45 Ponz DL, Sassatelli R, Benatti P, et al. Identification of hereditary nonpolyposis colorectal cancer in the general population. The 6-year experience of a population-based registry. Cancer 1993;71:3493-501.

46 Cornaggia M, Tibiletti MG, Albarello L, et al. Low incidence of hereditary nonpolyposis colorectal cancer syndrome in a selected area of the Lombardy Cancer Registry. Tumori 2000;86:439-44.

47 Aarnio M, Sankila R, Pukkala E, et al. Cancer risk in mutation carriers of DNA-mismatch-repair genes. Int J Cancer 1999;81:214-18.

48 Storm HH, Manders T, Friis S, et al. Cancer incidence in Denmark 1990. Danish Cancer Society, 1994

49 Wiinen J, Khan PM, Vasen H, et al. Hereditary nonpolyposis colorectal cancer families not complying with the Amsterdam criteria show extremely low frequency of mismatch-repair-gene mutations. Am J Hum Genet 1997:61:329-35.

50 Katballe N, Bentzen SM, Christensen $M$, et al. Role of chance in familial aggregation of colorectal cancer. Br J Cancer 2001;84:1084-6.
51 Rodriguez-Bigas MA, Boland CR, Hamilton SR, et al. A National Cancer Institute Workshop on Hereditary Nonpolyposis Colorectal Cancer Syndrome: meeting highlights and Bethesda guidelines. J Natl Cancer Inst 1997:89:1758-62.

52 Beck NE, Tomlinson IP, Homfray T, et al. Use of SSCP analysis to identify germline mutations in HNPCC families fulfilling the Amsterdam criteria. Hum Genet 1997:99:219-24.

53 Dunlop MG, Farrington SM, Carothers AD, et al. Cancer risk associated with germline DNA mismatch repair gene mutations. Hum Mol Genet 1997;6: 105-10.

54 Liu B, Farrington SM, Petersen GM, et al. Genetic instability occurs in the majority of young patients with colorectal cancer. Nat Med 1995; 1:348-52.

55 Marcus VA, Madlensky L, Gryfe R, et al. Immunohistochemistry for hMLH1 and hMSH2: a practical test for DNA mismatch repair-deficient tumors (in process citation). Am J Surg Pathol 1999;23:1248-55.

56 Cawkwell L, Gray S, Murgatroyd H, et al. Choice of management strategy for colorectal cancer based on a diagnostic

immunohistochemical test for defective mismatch repair. Gut 1999;45:409-15. 